\title{
Axillary Thoracotomy
}

Axillary thoracotomy may be used for the following procedures:

1. Upper thoracic sympathectomy.

2. Monaldi-McArthur drainage procedure for an emphysematous bulla.

3. Apical pleurectomy.

4. Access to lesions of the ailla

\subsection{Procedure}

With the patient in the lateral position, an incision is made with a knife in the lowest axillary skin crease (Fig. 12.1). The

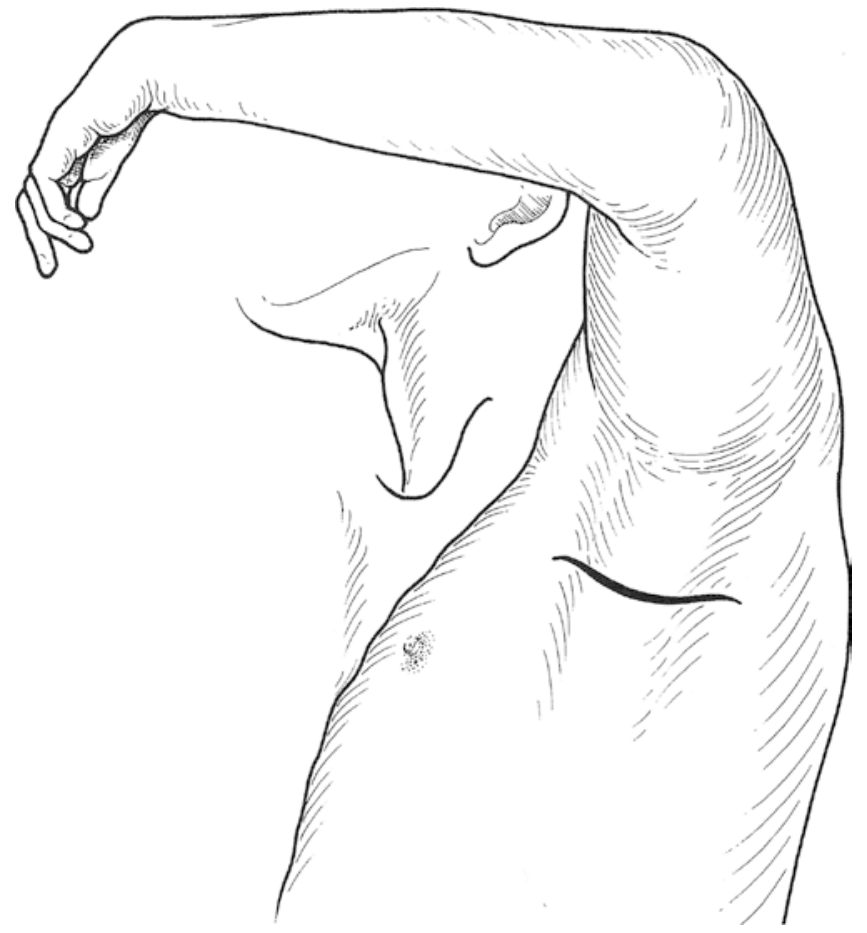

Fig. 12.1 With the patient in the lateral position, an incision is made with a knife in the lowest axillary skin crease incision is deepened through the fat using diathermy until the chest wall is reached. With this approach the incision enters the axillary space between the pectoralis and latissimus dorsi muscles, there being no need to cut either.

The chest is entered through the third intercostal space. The periosteum over the third rib is incised with diathermy and the intercostal muscle stripped from the rib with a rugine (Fig. 12.2). The underlying periosteum and pleura are incised with a knife. The incision is carried as far forwards as is necessary to obtain satisfactory exposure. Usually a smaller rib spreader than a Finochietto is required.

The wound is closed with a nylon stitch for the intercostal muscle layer, and absorbable sutures for the fat layer and the skin.

The pleural space should be drained as described previously.

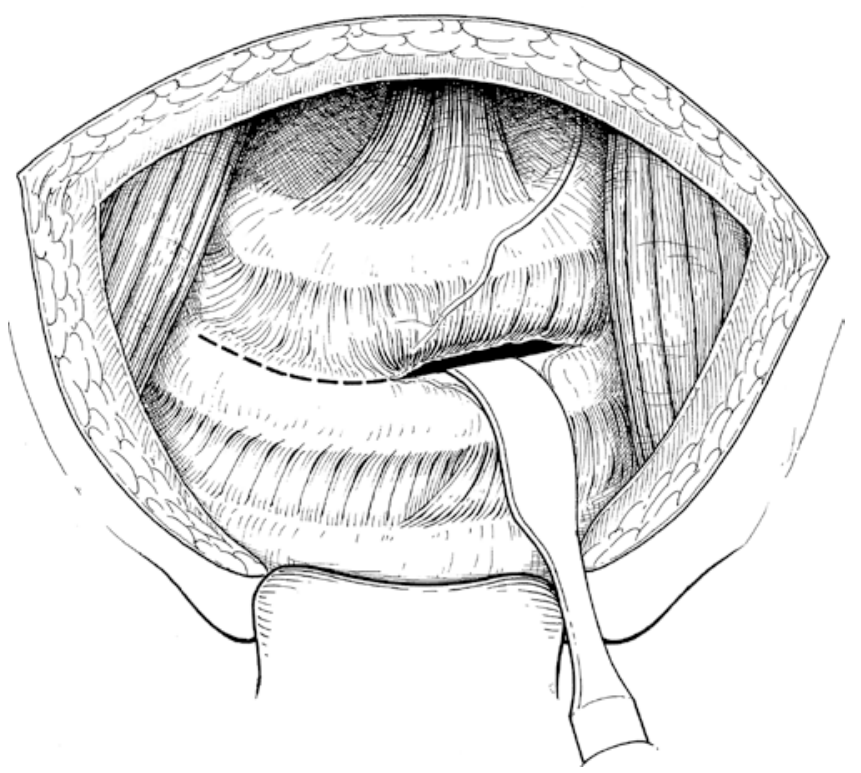

Fig. 12.2 The chest is entered through the third intercostal space. The periosteum over the third rib is incised with diathermy and the intercostal muscle stripped from the rib with a rugine. The underlying periosteum and pleura are incised with a knife 